\title{
Construção de um Sistema de Monitoramento do Ambiente Online - SIMÃO
}

\author{
Jamerson F.L. Lopes', Maria Y.F. Barbosa' ${ }^{1}$, Évila T.S. Freire' ${ }^{1}$, José F.S. Fonsêca', \\ Carlos B. Araújo', Daniel C. Lima'
}

\author{
'Instituto Federal de Educação Tecnológica do Rio Grande do Norte (IFRN) - Campus \\ Ipanguaçu \\ Ipanguaçu - RN - Brasil \\ cabarau@gmail.com, daniel.lima@ifrn.edu.br
}

\begin{abstract}
In the present work, we have built an Online Environmental Monitoring System using an Arduino-like board, which is an open-source electronics platform that reads inputs from the environment and turn it into information and/or tasks. Our system is able to detect variables such as temperature, humidity, luminosity and $\mathrm{CO} 2$ and record them every minute into a micro SD card. We have attached the system into a closed artificial ecosystem that is monitored $24 \mathrm{~h}$ per day. This platform can be used as an interdisciplinary tool by high school teachers, mainly in biology, ecology, chemistry, physics, informatics and electronics subjects, turning the classes more pleasant and profitable.
\end{abstract}

Resumo. No presente trabalho, construímos um Sistema de Monitoramento do Ambiente Online usando uma placa do tipo Arduino, que é uma plataforma eletrônica open-source que le inputs do ambiente transformando-os em informações elou tarefas. Nosso sistema é capaz de detectar variáveis como temperatura, umidade, luminosidade e CO2 e gravá-las a cada minuto em um cartão SD. Nós colocamos o sistema em um terrário artificial fechado que é monitorado 24 h do dia. Esta plataforma pode ser usada como uma ferramenta interdisciplinar por professores do Ensino Médio principalmente nas disciplinas de biologia, ecologia, química, física, informática e eletrônica, deixando as aulas mais agradáveis e proveitosas.

\section{Introdução}

É comum o sentimento entre os professores de ciências que está havendo uma diminuição no rendimento dos alunos quando comparado às gerações anteriores [Pozo e Crespo 2009]. Esse fato deve-se não apenas às mudanças ocorridas nas bases curriculares, mas também ao crescente desinteresse e falta de motivação por parte dos estudantes. O despreparo docente, a falta de laboratórios ou estratégias de ensino, levam a um excesso de aulas expositivas, o que dificulta a aprendizagem de certos conteúdos [Morais 2013]. Todas essas questões levam à necessidade do desenvolvimento de novos métodos de ensino, buscando alternativas para retirar o estudante de dentro da sala de aula tradicional. Uma das possibilidades de inovação no ensino de ciências é a construção do conhecimento científico a partir da união entre a pesquisa e a prática [Carvalho 2004].

Utilizando a abordagem sócio-histórica de Lev Vygotsky que preza pela interdisciplinaridade, além do Projeto Político Pedagógico do IFRN que coloca o trabalho interdisciplinar como um dos pilares da instituição [IFRN 2011], buscamos construir um Sistema de Monitoramento do Ambiente Online, que batizamos de SIMÃO. O SIMÃ̃ foi utilizado para monitorar um terrário fechado com plantas e isolado do ambiente externo. Além de sua utilidade em pesquisa, o ecossistema artificial monitorado pelo SIMÃO servirá como laboratório de aulas práticas de Biologia, e tem o 
VII Congresso Brasileiro de Informática na Educação (CBIE 2018)

Anais do XXIX Simpósio Brasileiro de Informática na Educação (SBIE 2018)

potencial de evidenciar processos biológicos em diferentes escalas, que vão desde a escala celular (fotossíntese ou respiração) aos processos biogeoquímicos [LEVIN 1992]. Adicionalmente, o sistema permite que docentes de outras disciplinas explorem tópicos que vão além da própria biologia, como as reações químicas envolvidas na fotossíntese e respiração celular, ou ainda as ondas eletromagnéticas envolvidas nesses processos, além de disciplinas de informática e eletrônica.

\section{Metodologia}

Para a construção do SIMÃO usamos uma placa do tipo Arduino com diferentes sensores para captar umidade e temperatura do ar (DHT-22), umidade do solo (higrômetro), luminosidade (BH1750) e concentração de CO2 (MQ-135). O acionamento das lâmpadas foi realizado por meio de um módulo relé. Os dados são armazenados minuto a minuto em um arquivo txt por meio de um módulo de cartão Micro SD, com o tempo controlado pelo módulo RTC (DS3231). As planilhas geradas podem ser abertas em Excel ou qualquer programa de análise, como o R. Essas análises tem sido realizadas em sala de aula, de forma a contribuir com a apropriação de conteúdos como a bioquímica ou ecologia. A programação foi realizada utilizando-se a linguagem do Arduino, e toda interface de análise foi realizada utilizando-se o software R. Dessa forma, toda a parte de programação do projeto pode ser facilmente disponibilizada.

\section{Resultados e discussão}

O principal produto desse projeto foi a construção de um sistema de monitoramento do meio ambiente (SIMÃO; Figura 1), que nesse momento temos aplicado nas aulas de biologia do IFRN.

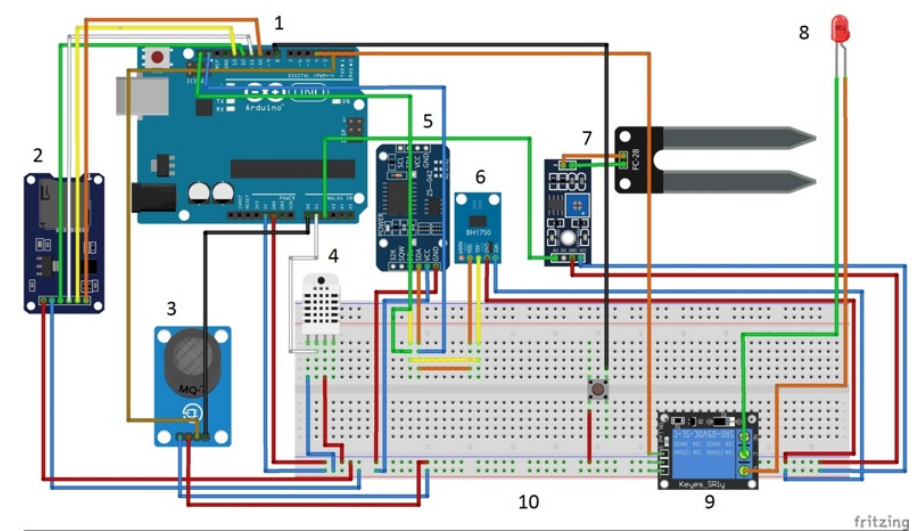

Figura 1. Esquema de prototipagem do SIMÃO. 1) Placa de tipo Arduino; 2) Módulo de cartão Micro SD; 3) Sensor de gases tóxicos MQ-135; 4) Sensor de temperatura e umidade DHT-22; 5) Módulo RTC; 6) Sensor de luminosidade BH-1750; 7) Sensor de umidade do solo; 8) lâmpada; 9) Relé; 10) Protoboard.

Quando associado a um terrário fechado, o SIMÃO pode ser utilizado em diferentes matérias do ensino médio/técnico. Com o dispositivo, acreditamos que o processo de ensino-aprendizagem dar-se-á de maneira mais eficiente, a partir de uma lógica Vygotsyana, onde o aluno sairá da abstração do conhecimento e partirá para a concretude do mesmo, levando a uma aprendizagem mais significativa [Nunes e Silveira 2015]. Nesse momento, temos implementado experimentos que buscam verificar como a fotossíntese ou a respiração celular afetam a concentração de $\mathrm{CO}_{2}$ (Figura 2), como diferentes comprimentos de onda ou temperatura influenciam a taxa da fotossíntese, e como esses processos, que ocorrem em nível de indivíduo, afetam o 
VII Congresso Brasileiro de Informática na Educação (CBIE 2018)

Anais do XXIX Simpósio Brasileiro de Informática na Educação (SBIE 2018)

ecossistema como um todo. O SIMÃO nos permite verificar essa oscilação em tempo real, tornando as aulas mais dinâmicas e práticas.

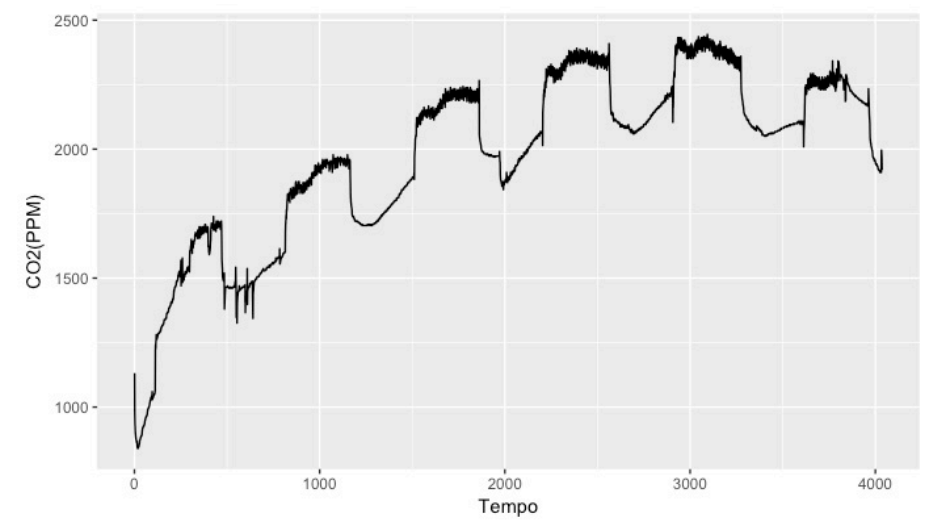

Figura 2. Gráfico mostrando a variação na concentração de dióxido de carbono entre o dia e noite no ecossistema fechado ao longo de seis dias.

\section{Conclusões e perspectivas}

O Sistema de Monitoramento do Ambiente Online (SIMÃO) é uma excelente ferramenta de pesquisa e ensino construída a partir de sensores associados a um microcontrolador. Por meio desse aparato, podemos realizar trabalhos principalmente na área de biologia e ecologia, além de levar o conhecimento prático para dentro da sala de aula nessas e em outras disciplinas, permitindo a utilização da abordagem sócio-histórica (interdisciplinar) de Vygotsky. Essas atividades consistem em experimentos que buscam mostrar, em sala de aula, como a fotossíntese é afetada por mudanças na temperatura, luminosidade, e comprimento de onda, e como esse tipo de mudança pode afetar os ecossistemas como um todo. Como perspectiva, pretendemos atualizar o SIMÃO para as varáveis serem monitoradas remotamente, além da inserção de um display LCD para monitorar os terrários.

\section{Referências}

Carvalho, A.M.P. (Org.) (2004) "Ensino de ciências: Unindo a pesquisa e a prática", Cengage Learning, São Paulo/SP, $1^{\mathrm{a}}$ edição.

INSTITUTO FEDERAL DO RIO GRANDE DO NORTE (IFRN) (2011). "Projeto político pedagógico do IFRN: uma construção coletiva", EduIFRN, Natal/RN.

Levin, S.A. (1992) "The problem of pattern and scale in ecology: the Robert H. MacArthur award lecture. Ecology, v. 73, n. 6, p. 1943-1967

Morais, R. (Org.) (2013) “Sala de aula: que espaço é esse?”, Papirus, São Paulo/SP, 24a edição.

Nunes, A.I.B.L., Silveira, R.N. (2015) "Psicologia da Aprendizagem", EdUECE, Fortaleza/CE, $3^{\mathrm{a}}$ edição.

Pozo, J.I., Crespo, M.A.G. (2009) "A aprendizagem e o ensino de ciências: Do conhecimento cotidiano ao conhecimento científico", Artmed, Porto Alegre/RS, $5^{\text {a }}$ edição. 